\title{
A technology-based approach to revitalise indigenous languages and cultures in online environments
}

\author{
Evaristo Ovide \\ Universidad de Salamanca \\ Paseo de Canalejas, 169, \\ 37008 Salamanca \\ (+34) 923294500 (ext. 3433) \\ evaristo_ovide@usal.es
}

\author{
Francisco José García-Peñalvo \\ GRIAL Research Group, \\ University of Salamanca \\ Paseo de Canalejas 169, 37008 \\ Salamanca, Spain \\ (+34) 923294500 (ext. 3433) \\ fgarcia@usal.es
}

\begin{abstract}
In this paper, we will show some facts showing the serious problems in the implementation of Intercultural Bilingual Education in the province of Chaco. The data provided here show that this education modality does not fulfill the expectations promised by the provincial or national governments. As a result indigenous languages and cultures in the province keep fading away under the pressure of the Spanish language, different religious denominations and other non-indigenous influences.

We propose here a technology-based education approach to revitalise indigenous languages as a main objective, as it is the most difficult and more powerful from an identity point of view, as we will argue in this paper. Cultural features evolve and change over time, but language is the link that keeps the past and the present together under the same identity.
\end{abstract}

\section{CCS Concepts}

-Applied computing E-learning • Applied computing Ethnography •Applied computing Collaborative learning

\section{Keywords}

E-learning; collaborative learning; indigenous peoples; endangered languages; decolonization.

\section{INTRODUCTION}

When the Spaniards governing Argentina decided to declare their independence from Spain in 1916 and rule the conquered lands themselves, the country was about half the size it is today. They would continue the conquest to new unclaimed (by white people) territories, such as the Patagonia (from Buenos Aires to Tierra del Fuego) and what we know today as the provinces of Chaco and Formosa. The conquest of what is now the province of Chaco ${ }^{1}$ started after the War of the Triple Alliance (1864 - 1870), in which Brazil, Uruguay and Argentina defeated Paraguay. After the war all three victorious countries set off to enlarge their national territories with Paraguayan lands and, at the same time, to invade indigenous territories no white man had conquered until then. The "Chaco Conquest" took place between 1870 a 1917 in several campaigns led by different generals. Among these, probably the best known is Gen. Victorica's campaign in 1884, who used massive military force against indigenous peoples who only had spears and bows, and ended most resistance in the area. Two elderly Wichi the author could interview (both passed away in 2015) still had the collective memory of the violent encounter in their territories with the conquering soldiers. Nowadays, three indigenous peoples in the province of Chaco survived the conquest: the Moqoit, the Qom and the Wichi. In Wichi territory, in the heart of a great territory full of forests in the north of the province, known as "The Impenetrable", an inhospitable arid and dry land that even nowadays gets totally isolated if a bit of rain falls on the dirt track that extends for $265 \mathrm{~km}$, lies the community I will refer to, the last indigenous people conquered in Argentina.

The first white man to live among them went there in 1971. Nowadays, Sip'ohi is no longer the name of the area, as the first mayor (another white man of the same group, who went there to bring "progress" and "civilization", and failed) called the municipality "El Sauzalito" when it was instituted in 1973. Such a recent contact with white society and the remoteness of the village explains their vulnerability as a people and the importance of a change in education, as will be explained in this paper.

\section{EDUCATION AND INDIGENOUS PEOPLES IN CHACO}

In 1922, the curriculum in the first schools established for indigenous children in Argentina (provinces of Formosa and Chaco) consisted, in its practical totality, of practical work (manual work, farming and agriculture for boys and manual work, washing, ironing and cooking for girls) and Spanish language, in equal parts [2]. This shows that the aim of educating indigenous children at school was to use them as cheap labour a first step. Later, the school system's main objective would be to force the white man's cultural system on them, effectively

1 The Province of Chaco, in Argentina, should not be confused with the geographical area known as Great Chaco, which is a much wider area including territories of Argentina, Bolivia, Paraguay and also part of Brazil. 
destroying the Wichi social system, their traditional values and their way of living and doing things as The only "right way" was the one being imposed on them, which was radically different.

There was no interest or concern about the indigenous student's first language or cultural background. The main aim of the school system was the most effective assimilation of the child into the dominant culture: "the school should pursue, as its main objective, to attract the aboriginal to civilized life" (National Counsel of Education, 1937, p. 303. Cited in [1]). The only valid language at school has traditionally been Spanish (and other than some symbolic presence of the indigenous language, it still is today). The most likely outcome in these circumstances would be drastic academic failure due to the non-trivial fact that the Wichi children simply did not understand the teacher and whatever they were being told.

In the $70 \mathrm{~s}$ and $80 \mathrm{~s}$, the indigenous movement in America started reclaiming their rights and demanding respect and participation. As a result, governments started changing the wording of the laws regarding indigenous education.

In 1987, the province of Chaco approved the Law of the Aboriginal of Chaco [5], with Chapter 3 dedicating three articles to talk about a type of education that should be "bicultural and bilingual" (Art. 15). That same year, the CIFMA Teacher Training Centre was created in the province to train aboriginal teaching assistants in 1989 and then, only intercultural bilingual teachers from 1994.

The Argentinean National Law of Education in 2006 [11] included a Chapter 11 with three articles establishing Intercultural Bilingual Education as a modality of the national education system. In theory, this type of education "promotes a mutually enriching exchange of knowledge and values between indigenous peoples and ethnically, linguistically and culturally different populations. This favours acknowledgement and respect to such differences" (Art. 52).

In 2010, the Chaco Government declared the Qom, Wichi and Moqoit languages official in the province, together with Spanish (Law 6604). The next year, that language officiality was regulated by means of Decree 257, establishing the measures that had to be taken regarding the rights of the speakers of those languages, which included the foundation of an Academy of Indigenous Languages, among many other things.

The province of Chaco is, by far, the province in Argentina where Intercultural Bilingual Education has more relevance, not just by the number of laws passed in favour of indigenous languages, teachers or rights, but also because indigenous peoples in the north still are considerably numerous and some of them, unlike in most of Argentina, they still speak their traditional languages.

\section{INTERCULTURAL BILINGUAL EDUCATIONAFTER 25 YEARS}

In 2011, a report was published [13] on the socio-educative situation of children and teenagers in two Qom communities in the area of Resistencia, the capital of the province. Some illustrative results are the following:

1) Regarding children between 8 an 14 years old:

Community A: $21.4 \%$ are $0-1$ years behind in their studies; $29.3 \%$ are two years behind; $49.3 \%$ are three or more years behind at school.

Community B: $12.5 \%$ are $0-1$ years behind in their studies; $25 \%$ are two years behind; $62,5 \%$ are three or more years behind at school.

2) Regarding teenagers between 15 and 19 years old:

Community A: Only $49.4 \%$ are studying; $5.1 \%$ of them study at the same level as children between 6 and 8 years old; $41 \%$ study with children aged 9 to $11 ; 5.1 \%$ with children aged 12;33\% with children aged $13-14$ and $15.4 \%$ with students aged 15 to 17 years old. In other words, only 3 out in 10 teenagers between 15 and 19 in that community are, in the best scenario, studying in the level they should.

Community B: Only $40 \%$ of teenagers aged 15 to 19 are studying; $8.3 \%$ of them study with children aged 6 to $8 ; 50 \%$ of them study at 9 to 11 level; $29.2 \%$ at 12-year-old level and only $12,5 \%$ of those studying are doing it at their right level (15-17), in the best possible scenario.

These results show how indigenous students are performing in the surroundings of the capital and are much worse than those of nonindigenous students in the area. Elena Duro, Head of Education at UNICEF Argentina, said at the presentation of the report "The inequality gap between indigenous and non-indigenous children demands strong measures by the National and provincial governments" [9]. It is important to note that in the capital roads are paved, there are frequent buses, equipped hospitals and clinics, libraries, supermarkets and things one would normally expect in a city. Chaco is among the poorest provinces in Argentina and rural areas can be extremely rural, especially in the area known as "The Impenetrable", which occupies about half of the whole province. In many areas of the province, when it rains, children do not go to school because the dirt road becomes impracticable. Furthermore, as one goes north from the capital, poverty reaches much higher levels, especially in "The Impenetrable", which is mostly Wichi territory.

\section{WHY DOES INTERCULTURAL BILINGUAL EDUCATION NOT WORK IN CHACO?}

Initiatives from governments responding to indigenous demands (education in this case) tend to lack a fundamental element: evaluation. Laws are passed, processes are promoted in schools, houses are given away to indigenous families, but there is usually no assessment to measure the application of those laws, the performance of children in the schools or the quality of the houses built. The demolishing report from UNICEF was published after over 20 years of having indigenous teachers in schools. I will mention only a few facts about the system that shed some light on why such appalling results were obtained.

Intercultural Bilingual Teachers have been trained since 1994, but the curriculum specific to them was not published until 2013 (initial and primary levels) and 2014 (secondary level). If indigenous teachers did not have a specific curriculum to teach in 20 years, they could not evaluate their students in any subject other than the ones any non-indigenous teacher would teach them. 
In 2011, Decree 257 was published to regulate the officiality of the three indigenous languages declared the previous year. Article 4.3 of this decree establishes that the Provincial Advising Counsel of Indigenous Languages (a counsel created by the law this decree is regulating) would propose the creation of the Academy of the Indigenous Languages of the Province. This, among many other things that the Law 6604 and this decree mandated, was never actually carried out so far (five years later). The great gap between apparent progress made in paper (even if they are laws passed by the Chaco Parliament) could even be seen as intentional. At the beginning of this year, a member of Parliament [4] proposed the creation of the Institute of Indigenous Languages of Chaco at the beginning of this year. All laws regarding indigenous communities in Chaco are government initiatives which are proposed to communities (not the other way around) and approved. This Member of Parliament, who knows Law 6604 (specifically mentioned in her proposal) and its Decree 257, decides to propose the creation of an institution that was mandated already by a law approved 5 years before...

In all these years, practically no indigenous person has obtained a university degree in Chaco, despite the fact that the main public university in the province offers grants for indigenous people since 2011. Taking into account the generalised extreme poverty in indigenous areas, the Wichi people have little options other than study to become an Intercultural Bilingual Teacher in their village. All public servants in that area of The Impenetrable, due to its remoteness and what that involves, earn almost three times the salary of a teacher in the capital of the province. This creates a great fracture among Wichi people: on the one hand, those Wichi who became teachers have a great quality of life and their problems are not the problems of the Wichi people anymore. Their concerns now are those of the teachers. On the other hand, most Wichi people, who are not teachers or public servants, basically depend on national subsidies, charity and they live in extremely poor conditions.

An educational system that is often described by the government as fulfilling the needs of indigenous people (even if the laws are not really applied) can be very dangerous. That makes indigenous teachers and parents think that no demand for change is appropriate, even though Wichi students as a whole keep clearly failing to reach success in the school system. Only those who adapt to the ways of the dominant culture and language can be successful in life. The public message is respect for indigenous cultures and language and an educational system adapted to their needs, whereas the subtle message indigenous people receive is that either they become white in language and forms or they will stay poor and out of the system.

The argument sustained here is that few States, if any at all, will use the school system to really promote the language and identity of a people that was violently conquered by the culture who currently conform the dominant class in the country. All across America indigenous peoples (those who were living in the place when white people invaded and conquered them) are a minority in their state. Even if they are over 30 million indigenous people, as is the case in Mexico, they are a minority. On top of that, being indigenous in Latin America implies being part of a poor minority and living in the poorest areas with less development, including education [8].

The more poverty is present in somebody's life, the less room is left for concerns about identity, traditions and culture. The main problem most indigenous peoples face is surviving in the capitalist society that has been imposed on them, being able to feed their children, obtaining subsidies or fighting for their rights in an alien system they often do not understand very much. Not mastering the language of the dominant culture or having totally opposed moral values regarding nature, human relationships or what "progress" means presents a difficult problem to solve in the "integration" process, which tends to be a politically correct word to refer to assimilation or whitening of the indigenous people. When the education system is promoting the views of the dominant culture and assimilation or marginalization seem to be the only options to succeed in life, a great deal of motivation, support from professionals and strong internal organization within the indigenous people (three elements not likely to happen at the same time) are required in order to change things.

\section{THE TECHNOLOGICAL OPTION TO ACHIEVE CHANGE}

Change seems an extremely remote goal in the conditions described above. However, the massive introduction in the market of smartphones with data plans has reached places as far as the Impenetrable, where a decent Internet connection had been till then just a distant dream. Although not every indigenous person can afford a smartphone and pay a monthly data plan, indigenous teachers and those working in the Administration in such a remote area are very well paid to make up for their working location. As a result, we could say that most, if not all, indigenous teachers are connected to the Internet and social networks such as facebook.

Also, national programs like "Conectar Igualdad"2 (2010-2016) provided netbooks to all students and teachers in public secondary school, special education and teacher training centres in the country. It also provided Internet access (with variable results depending on the place) to all public centres. Although suspended this year by the new national government, this program provided many households with computers they could have never obtained in any other way due to the poverty they suffer.

As a result, we can appreciate that some hardware and some Internet access are available to, at least, most indigenous teachers and many indigenous students. This is a basic starting point to design some online strategy to reverse the language and cultural shift we have described.

The general technology-based model that we propose for language and culture revitalisation is based on five broad phases, not necessarily consecutive, that are interconnected. More detailed information on this model can be obtained in [12].

\subsection{Documentation}

This is an important and often an extremely urgent matter as traditional manifestations and languages are being lost with the death of the older members of the communities. If cultural practices or languages are not documented, they could be lost forever. However, they should not be the only focus of researchers, as it is still common nowadays. Sciences such as Anthropology, Linguistics or Ethnography still

2 http://www.conectarigualdad.gob.ar/ 
continue, to a certain extent, the focus from previous centuries of documenting, classifying, tagging and preserving in some controlled environment, such as a library, a museum or a zoo, but without any real interest about protecting, promoting or revitalising whatever it was being studied. Whether it was an animal, a plant or an indigenous person, they all received the same consideration and digging out somebody's skeleton from an indigenous cemetery to show it to the public in a museum apparently did not pose any ethical problems then. It is our view that research should benefit science and the indigenous community in equal parts.

\subsection{Communication}

This is an essential point in order to promote a language, to share a particular way of seeing the world, to rescue the knowledge of the few elders who still remember forgotten words or pre-missionaries spiritual rituals. Taking into account that many indigenous communities can be very far from each other, logging onto some mobile app where people can organise themselves in groups and communicate to each other online makes a great difference. When an ever-growing number of members of an indigenous people join an online group, more initiatives can be started and more collaboration can take place.

\subsection{Dissemination}

There was a time when whatever was not present on the television, it mostly did not exist. Nowadays, we have a much more democratic source of news and information: the Internet. Since the implementation of the Web 2.0 or Read-Write Web, the user stopped being just a consumer of information (as it had previously been with the television), to become also a potential producer who could easily enrich the world with particular different points of view uploaded to the Internet in audio, video, text, picture or a combination of them. The more presence a language has online, the easier it will be normalised among their speakers and the more knowledge they will have about it. Also, the more visible a people and their traditions are on the Internet, the more probabilities there are of people becoming interested in them, in writing on them, in contacting them and in participating in projects to help them. The general public will hardly sympathize with or care about something they do not know it exists.

\subsection{Education}

Education and the school system are not necessarily the same thing. Education has always existed wherever there was a human group, passing knowledge, values and know-how from adults to children. The school system is a state-run institution (even private educational institutions need to satisfy the state's requirements to award officially recognised certificates) that aims at shaping all children uniformly into the type of citizen the Government thinks will be more appropriate in that particular society. This which might easily change when the political party in office is replaced by a different one and hence, the changes in the curricula when there is a power shift in any government. The problem is that the "ideal" citizen the school system seeks to create in all those compulsory years between four walls has a language, values and ideas very different from the ones indigenous students have. A massive and unlikely transformation has to happen in indigenous children to fit into that ideal and succeed in the school system.

Indigenous languages and cultural elements are not contents the school system wants the "ideal" citizen to acquire in those 10-14 years of compulsory training. That is the reason we believe that out-of-school educational activities are necessary if an effective learning in indigenous contents is really sought. Using digital technologies to complement and coordinate those educational activities would greatly benefit their efficiency and effectiveness. We should be clear that this proposal does not imply doing everything just through the Internet. We are promoting here the use of digital technologies as a complement in these tasks, not as a face-to-face substitute.

\subsection{Monetization}

Although this paper is about how to use the potential of digital technologies to revitalise indigenous languages (and their cultures in a broad sense), we cannot ignore the socio-economic factor. When a person is poor and has no means to feed their children, talking about identity, traditions and indigenous languages might seem totally irrelevant.

Cooper [6] presents the process of language planning in marketing terms: a product (the language), a group to sell the product to (potential speakers), an adequate promotion of the produet, a place to buy the product (existence of grammars, dictionaries, etc.), adequate price (the effort required to learn the language or to adjust to an academic norm has to be less that the benefit it provides). Going a step further, we believe that marketing should be used, not only as a metaphor used in language planning, but also for business situations where indigenous peoples could obtain an income. If a language and its culture are associated with poverty, social exclusion and unemployment, its members will most likely abandon it in a few generations in an effort to have a better quality of life integrating in the dominant culture that destroyed their traditional way of earning their living

To sum it up, to promote a language, we have to promote its speakers and their economy: "the way to preserve languages is to make languages economically and/or politically paying operations, even if only for a few people, like indigenous authors and indigenous publishers" [3].

\section{ONLINE COLLABORATION FOR LEARNING AND TEACHING INDIGENOUS LANGUAGES}

After this brief overview of the general technology-based model for revitalising indigenous languages and cultures, we will describe a proposal for putting this model into practice.

The objective of this proposal is to promote the Wichi language, spoken in the most remote area of the Impenetrable. Wichi people (most of them) still speak their traditional language due mainly to their remoteness and the racial segregation in the area. However, Spanish is replacing Wichi in more Wichi families as time passes, especially in mixed marriages. The fact that most students normally speak Wichi as their first language implies that the symbolic time devoted to language learning in the school consisted basically in learning how to write and read it, with a variable and not very consistent orthography. The extremely scarce language teaching resources and the lack of a 
methodology to teach the languages to non-native speakers limit to a great extent the possibilities of the language to grow. Taking into account their extreme vulnerability from a social, economic and political points of view (even compared to the other indigenous peoples in the province), language shift is growing and, unlike other languages, there is no method in place to recuperate lost speakers.

The methodology designed to fulfill the main objective is very innovative in research with indigenous people. Also very challenging, as we will see.

1) Traditionally, native speakers have always talked to linguists, answered questions so that the linguist documents the language. In this case, the innovation is that the aim is not just to document the language, but to speak the language, and that process will be done exclusively online.

Although people might think that linguists speak many languages because we study them, that is actually against the rule. Few linguists can actually have fluent conversations with the speakers of the language they publish about, as the main aim in academia is documentation of the language rather its revitalization. We believe that in order to create effective learning materials, the path of learning the language must have been trodden upon to identify the problems and the solutions. In this project, we are doing that process from a European city to a remote village in the Impenetrable area in the north of Argentina using different mobile apps to have voice conversation with small bandwidth consumption.

2) This language is not taught in the school system to non-Wichi students. There are no teaching materials and no methodology to teach the language at all. What indigenous Wichi teachers do regarding the language is teach native students to write and read the words they already know. As a result, the process of creating learning materials involves linguistic work finding out how the language works and then pedagogic work to convey that knowledge to the non-native speaker so they can learn the language.

3) Another innovative element in this project is that there is a strong ethical component to make sure that indigenous people are not the object of study, but members of the research team who also benefit from the research. Even if they were not interested in creating teaching materials for non-native speakers, the project involves a language exchange, whereby they teach the researcher Wichi and, in exchange, they receive English lessons.

4) Finally, this proposal includes the creation of a mobile app to learn the basics of the language. It will include audio, pictures and text and will have different sections like a glossary, common sentences and topics grouped by semantic field. It will be available free of charge for Android and iPhone and will be based on free software.

As explained before, this methodology presents strong challenges, like to secure the interest of non-researchers and to be flexible with times and circumstances when meeting online. However, we believe this will project will open a whole range of important opportunities in other non-language related fields, such as medical attention, for example.

\section{CONCLUSION}

Digital technologies have been use extensively in so many fields in our society. However, our aim is to put these opportunities in the hands of those who need them more and who have already the infrastructure to implement such projects. Being the last indigenous people to be colonised, just in the 70s, the Wichi people are very isolated in villages where racial segregation is practised at schools between indigenous and non-indigenous students. This explains that they still preserve their language and way of communicating (non-verbal language and other interaction aspects are very different).

However, precisely that isolation that helped them resist so far the language shift is the element that keeps them very far from the centres of power in the province and suffering more injustice than in other places.

We will finish this paper with the words of Krauss, which describe very well the level of commitment we consider necessary not only to achieve cultural and linguistic revitalization, but also from an ethical point of view, to establish a collaboration between researcher and indigenous community where both parts benefit instead of academic exploitation on the part of the researcher: "We should not only be documenting these languages, but also working educationally, culturally, and politically to increase their chances of survival. This means working with members of the relevant communities to help produce pedagogical materials and literature and to promote language development in the necessary domains, including television. And it involves working with communities, agencies, and, where possible, governments for supportive language planning" [8].

\section{REFERENCES}

[1] Acuña, L. 2010. Lenguas propias y lenguas prestadas. In La Educación Intercultural Bilingüe en Argentina. Identidades, lenguas y protagonistas, S. Hirsch and A. Serrudo. Noveduc, Buenos Aires, 344.

[2] Artieda, T. and Rosso, L. 2005. Pedagogía para indígenas del Chaco a fines del siglo XIX y principios del XX. La asimilación "dulce" por la vía de la educación y el trabajo. In El sistema educativo en Argentina. Nuevas perspectivas históricas, A. Ascolani. Ed. Laborde, Rosario (Argentina).

[3] Bernard, H.R. 1996. Language Preservation and Publishing. In Indigenous Literacies in the Americas: Language Planning from the Bottom up, N. H. Hornberger. Mouton de Gruyter, Berlin, p. 151.

[4] Canata, A.M. 2016. Proyecto de Ley 11/2016. http://segleg.chaco.gov.ar/legislatura/servlet/hconstramindiv?2016,1,11. Accessed: 2016- 08-31. 
[5] Chaco.

1987.

Ley

del

Aborigen

Chaqueño. http://www2.legislaturachaco.gov.ar:8000/legisdev/ResumenDocumento.aspx?docId=L.3258\&tipo=Ley. Accessed: 2016- 08- 31.

[6] Cooper, R.L. 1989. Language planning and social change. Cambridge University Press, Sydney.

[7] Crystal, D. 2000. This man is worth $£ 100,000$ a year. High Life (British Airways), 104-8. http://www.davidcrystal.com/?fileid=-4872. Accessed: 2016- 08- 31 .

[8] D'Emilio, L. 1994. Pobreza de la educación y propuestas indígenas: Lecciones aprendidas. In Educación y pobreza: de la desigualdad social a la equidad, Pieck Gochicoa, E. and Aguado López, E., El Colegio Mexiquense/UNICEF, Zinancatepec (Mexico).

[9] Duro, E. 2011. Niños y adolescentes indígenas: muy pocos terminan la escuela. http://www.unicef.org/argentina/spanish/media_20471.htm. Accessed: 2016- 08- 31.

[10] Krauss, M. 1992. The World's Languages in Crisis. Language, Vol. 68, N 1, p. 9.

[11] Nación, 2006. Ley Nacional de Educación. http://www.oei.es/quipu/argentina/ley_de_educ_nac.pdf. Accessed: 2016-08- 31.

[12] Ovide, E. 2013. Intercultural Education with Indigenous Peoples and the Potential of Digital Technologies to Make it Happen. In Multiculturalism in Technology-Based Education: Case Studies on ICT-Supported Approaches, F.J. García-Peñalvo. Igi Global, Hershey, PA, USA.

[13] UNICEF. 2011. Situación socioeducativa de niñas, niños y adolescentes de comunidades tobas. http://www.unicef.org/argentina/spanish/tobas_web.pdf. Accessed: 2016- 08- 31.

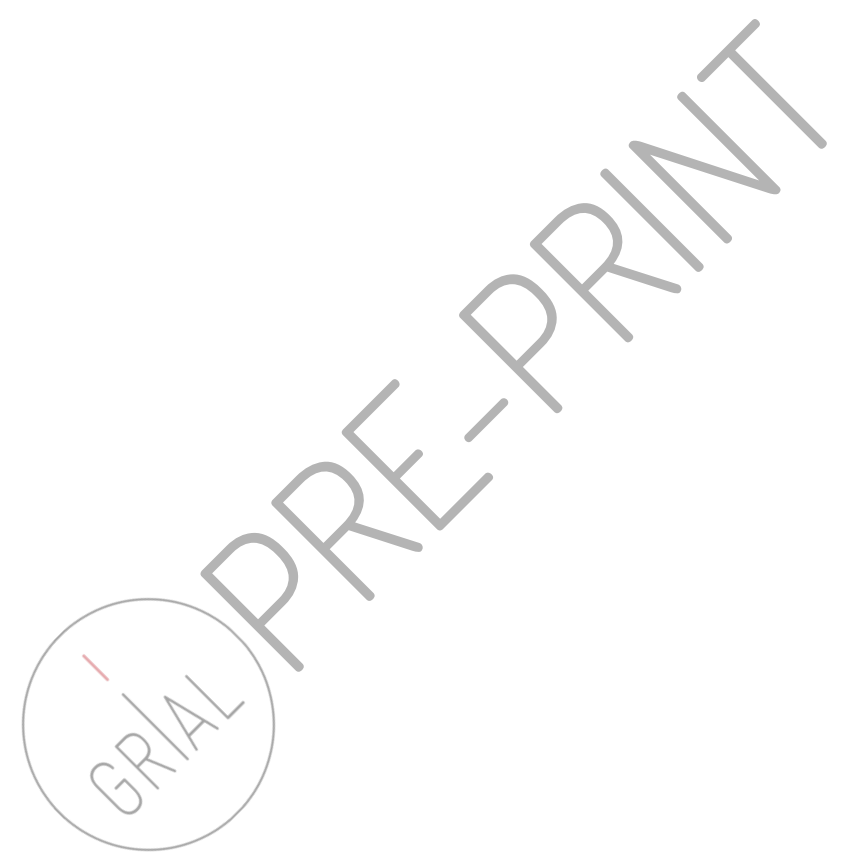

